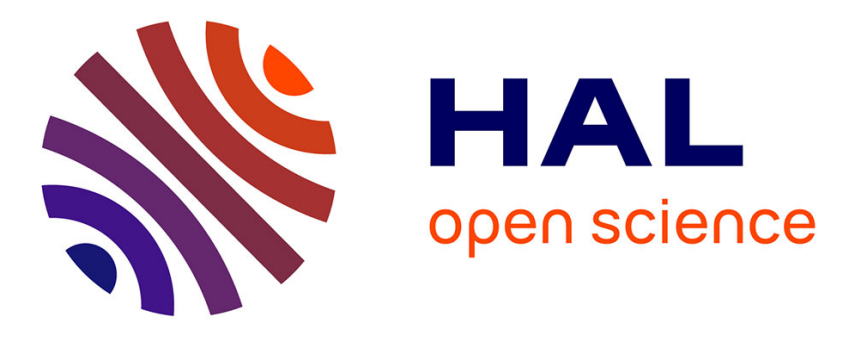

\title{
Design of new phenothiazine derivatives as visible light photoinitiators
}

\author{
Mahmoud Rahal, Mira Abdallah, Thanh-Tuan Bui, Fabrice Goubard, \\ Bernadette Graff, Frederic Dumur, Joumana Toufaily, Tayssir Hamieh, \\ Jacques Lalevee
}

\section{To cite this version:}

Mahmoud Rahal, Mira Abdallah, Thanh-Tuan Bui, Fabrice Goubard, Bernadette Graff, et al.. Design of new phenothiazine derivatives as visible light photoinitiators. Polymer Chemistry, 2020, 11 (19), pp.3349-3359. 10.1039/D0PY00497A . hal-02866907

\section{HAL Id: hal-02866907 https://hal.science/hal-02866907}

Submitted on 1 Jul 2020

HAL is a multi-disciplinary open access archive for the deposit and dissemination of scientific research documents, whether they are published or not. The documents may come from teaching and research institutions in France or abroad, or from public or private research centers.
L'archive ouverte pluridisciplinaire HAL, est destinée au dépôt et à la diffusion de documents scientifiques de niveau recherche, publiés ou non, émanant des établissements d'enseignement et de recherche français ou étrangers, des laboratoires publics ou privés. 


\section{Dear Author,}

Please use this PDF proof to check the layout of your article. If you would like any changes to be made to the layout, you can leave instructions in the online proofing interface.

Making your changes directly in the online proofing interface is the quickest, easiest way to correct and submit your proof. Please note that changes made to the article in the online proofing interface will be added to the article before publication, but are not reflected in this PDF proof.

If you would prefer to submit your corrections by annotating the PDF proof, please download and submit an annotatable PDF proof by following this link:

https://rscweb.proofcentral.com/en/offline.html? token=3a11ade7b3ccbb2b1408c50b6994b425 


\section{Polymer Chemistry}

We have presented the graphical abstract image and text for your article below. This briefly summarises your work, and will be presented with your article online.

1

\section{Design of new phenothiazine derivatives as visible light photoinitiators}

Mahmoud Rahal, Mira Abdallah, Thanh-Tuân Bui,* Fabrice Goubard, Bernadette Graff, Frédéric Dumur, * Joumana Toufaily, Tayssir Hamieh and Jacques Lalevée*

In this article, four new phenothiazine derivatives (denoted as PT1, PT2, PT3 and PT4) are specifically in silico designed by molecular modelling for good light absorption properties @ $405 \mathrm{~nm}$.

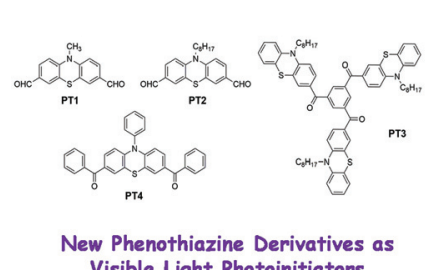

Visible Light Photoinitiators

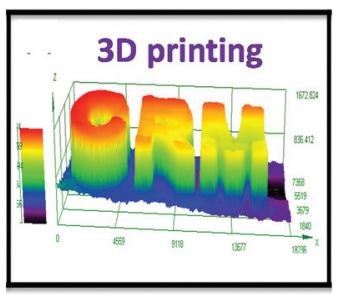

Please check this proof carefully. Our staff will not read it in detail after you have returned it.

Please send your corrections either as a copy of the proof PDF with electronic notes attached or as a list of corrections. Do not edit the text within the PDF or send a revised manuscript as we will not be able to apply your corrections. Corrections at this stage should be minor and not involve extensive changes.

Proof corrections must be returned as a single set of corrections, approved by all co-authors. No further corrections can be made after you have submitted your proof corrections as we will publish your article online as soon as possible after they are received.

Please ensure that:

- The spelling and format of all author names and affiliations are checked carefully. You can check how we have identified the authors' first and last names in the researcher information table on the next page. Names will be indexed and cited as shown on the proof, so these must be correct.

- Any funding bodies have been acknowledged appropriately and included both in the paper and in the funder information table on the next page.

- All of the editor's queries are answered.

- Any necessary attachments, such as updated images or ESI files, are provided.

Translation errors can occur during conversion to typesetting systems so you need to read the whole proof. In particular please check tables, equations, numerical data, figures and graphics, and references carefully.

Please return your final corrections, where possible within $\mathbf{4 8}$ hours of receipt following the instructions in the proof notification email. If you require more time, please notify us by email to polymersarsc.org. 


\section{Funding information}

Providing accurate funding information will enable us to help you comply with your funders' reporting mandates. Clear acknowledgement of funder support is an important consideration in funding evaluation and can increase your chances of securing funding in the future.

We work closely with Crossref to make your research discoverable through the Funding Data search tool (http://search. crossref.org/funding). Funding Data provides a reliable way to track the impact of the work that funders support. Accurate funder information will also help us (i) identify articles that are mandated to be deposited in PubMed Central (PMC) and deposit these on your behalf, and (ii) identify articles funded as part of the CHORUS initiative and display the Accepted Manuscript on our web site after an embargo period of 12 months.

Further information can be found on our webpage (http://rsc.li/funding-info).

\section{What we do with funding information}

We have combined the information you gave us on submission with the information in your acknowledgements. This will help ensure the funding information is as complete as possible and matches funders listed in the Crossref Funder Registry.

If a funding organisation you included in your acknowledgements or on submission of your article is not currently listed in the registry it will not appear in the table on this page. We can only deposit data if funders are already listed in the Crossref Funder Registry, but we will pass all funding information on to Crossref so that additional funders can be included in future.

\section{Please check your funding information}

The table below contains the information we will share with Crossref so that your article can be found via the Funding Data search tool. Please check that the funder names and grant numbers in the table are correct and indicate if any changes are necessary to the Acknowledgements text.

\begin{tabular}{|l|l|l|l|}
\hline Funder name & $\begin{array}{l}\text { Funder's main country } \\
\text { of origin }\end{array}$ & $\begin{array}{l}\text { Funder ID } \\
\text { (for RSC use only) }\end{array}$ & Award/grant number \\
\hline
\end{tabular}

\section{Researcher information}

Please check that the researcher information in the table below is correct, including the spelling and formatting of all author names, and that the authors' first, middle and last names have been correctly identified. Names will be indexed and cited as shown on the proof, so these must be correct.

If any authors have ORCID or ResearcherID details that are not listed below, please provide these with your proof corrections. Please ensure that the ORCID and ResearcherID details listed below have been assigned to the correct author. Authors should have their own unique ORCID iD and should not use another researcher's, as errors will delay publication.

Please also update your account on our online manuscript submission system to add your ORCID details, which will then be automatically included in all future submissions. See here for step-by-step instructions and more information on author identifiers.

\begin{tabular}{|l|l|l|l|}
\hline First (given) and middle name(s) & Last (family) name(s) & ResearcherID & ORCID iD \\
\hline Mahmoud & Rahal & & \\
\hline Mira & Abdallah & & \\
\hline Thanh-Tuân & Bui & & $0000-0002-5367-2738$ \\
\hline Fabrice & Goubard & & \\
\hline Bernadette & Graff & & \\
\hline Frédéric & Dumur & & $0000-0003-4872-094$ X \\
\hline Joumana & Toufaily & & \\
\hline Tayssir & Hamieh & C-2045-2013 & $0000-0003-2153-7408$ \\
\hline Jacques & Lalevée & & $0000-0001-9297-0335$ \\
\hline
\end{tabular}




\section{Queries for the attention of the authors}

\section{Journal: Polymer Chemistry Paper: d0py00497a}

\section{Title: Design of new phenothiazine derivatives as visible light photoinitiators}

For your information: You can cite this article before you receive notification of the page numbers by using the following format: (authors), Polym. Chem., (year), DOI: 10.1039/d0py00497a.

Editor's queries are marked like this Q1, Q2, and for your convenience line numbers are indicated like this $5,10,15, \ldots$

Please ensure that all queries are answered when returning your proof corrections so that publication of your article is not delayed.

\begin{tabular}{|c|c|c|}
\hline $\begin{array}{l}\text { Query } \\
\text { Reference }\end{array}$ & Query & Remarks \\
\hline Q1 & $\begin{array}{l}\text { Please confirm that the spelling and format of all author names } \\
\text { is correct. Names will be indexed and cited as shown on the } \\
\text { proof, so these must be correct. No late corrections can be } \\
\text { made. }\end{array}$ & \\
\hline Q2 & $\begin{array}{l}\text { Please check that the addresses and affiliation links have been } \\
\text { displayed correctly. }\end{array}$ & \\
\hline Q3 & $\begin{array}{l}\text { The sentence beginning "The FRP of } 1.4 \mathrm{~mm} \text { thick samples..." } \\
\text { has been altered for clarity. Please check that the meaning is } \\
\text { correct. }\end{array}$ & \\
\hline Q4 & $\begin{array}{l}\text { In the sentence beginning "For the benchmark } 2 \text { - } \\
\text { isopropylthioxanthone/lod..." should "interest" be changed to } \\
\text { "potential"? }\end{array}$ & \\
\hline Q5 & $\begin{array}{l}\text { The sentence beginning "The ability of the different..." has been } \\
\text { altered for clarity. Please check that the meaning is correct. }\end{array}$ & \\
\hline Q6 & $\begin{array}{l}\text { Please check that "Rp" has been displayed correctly in the } \\
\text { sentence "The efficiency for CP ...". }\end{array}$ & \\
\hline Q7 & $\begin{array}{l}\text { Please check that "1phenothiazine" has been displayed correctly } \\
\text { in Table } 3 .\end{array}$ & \\
\hline Q8 & $\begin{array}{l}\text { Please note that a conflict of interest statement is required for } \\
\text { all manuscripts. Please read our policy on Conflicts of interest } \\
\text { (http://rsc.li/conflicts) and provide a statement with your proof } \\
\text { corrections. If no conflicts exist, please state that "There are no } \\
\text { conflicts to declare". }\end{array}$ & \\
\hline Q9 & $\begin{array}{l}\text { Ref. 21: Please check that the last name for the 6th author is } \\
\text { displayed correctly. }\end{array}$ & \\
\hline Q10 & $\begin{array}{l}\text { Ref. 24: Please check that the last name for the 1st author is } \\
\text { displayed correctly. }\end{array}$ & \\
\hline Q11 & $\begin{array}{l}\text { Ref. 35: Please check that the journal title has been displayed } \\
\text { correctly. }\end{array}$ & \\
\hline
\end{tabular}




\title{
Design of new phenothiazine derivatives as visible light photoinitiators
}

\author{
Mahmoud Rahal, a,b,c Mira Abdallah, a,b,c Thanh-Tuân Bui, (D) *d Fabrice Goubard, ${ }^{d}$ \\ Bernadette Graff, ${ }^{a, b}$ Frédéric Dumur, (D) *e Joumana Toufaily, ${ }^{c}$ Tayssir Hamieh (D) c,f \\ and Jacques Lalevée $\mathbb{D} * a, b$
}

In this article, four new phenothiazine derivatives (denoted as PT1, PT2, PT3 and PT4) are specifically in silico designed by molecular modelling for good light absorption properties $a 405 \mathrm{~nm}$. The most interesting structures showing both intense violet/blue light absorption and high potential photochemical reactivity were synthesized for detailed investigations as photoinitiators/photosensitizers in the presence of an iodonium salt for the free radical photopolymerization of (meth)acrylates and the cationic polymerization of epoxides upon near-UV or visible light irradiation. Remarkably, two of the proposed structures (PT3 and PT4) from this in silico design were never synthesized prior to this work and were thus specifically designed for this work. Three-component photoinitiating systems based on PT/iodonium/amine ( $N$-phenylglycine or ethyl 4-dimethylaminobenzoate) are also developed for the free radical polymerization of acrylates. Both excellent polymerization rates and high final reactive function conversions were obtained. A full picture of the photochemical mechanisms is provided using different techniques: realtime Fourier transform infrared spectroscopy, UV-visible spectroscopy, fluorescence spectroscopy, and cyclic voltammetry. Finally, the high performance of the phenothiazine derivatives is also shown in 3D

Received 4th April 2020 Accepted 30th April 2020

DOI: $10.1039 /$ d0py00497a rsc.li/polymers printing experiments as well as in photocomposite synthesis using glass fibres (thick sample; using a LED@395 nm conveyor).
${ }^{a}$ Université de Haute-Alsace, CNRS, IS2 M UMR 7361, F-68100 Mulhouse, France.

E-mail: jacques.lalevee@uha.fr

${ }^{b}$ Université de Strasbourg, Strasbourg, France

${ }^{c}$ LEADDER and MCEMA Laboratories, EDST, Faculty of Sciences,

Lebanese University, Hadath, Lebanon

\section{Introduction}

Cationic (CP) and free radical (FRP) polymerization reactions induced by UV light have been widely encountered since decades in the field of irradiation hardening and they constitute a powerful tool for the preparation of functional coatings. ${ }^{1}$ Nowadays, light emitting diodes (LEDs) are classically used as irradiation sources, because of their numerous advantages compared to the traditional UV mercury lamps or lasers (low heat generation, low energy consumption, low operating costs, long lifetime, portability, simple and safe handling, possible integration in compact 3D printers, etc.). ${ }^{2-4} \mathrm{~A}$ photoinitiator (PI) is required to convert light to initiating species. Therefore,

${ }^{d}$ CY Cergy Paris Université, LPPI, F-95000 Cergy, France. E-mail: tbui@cyu.fr

${ }^{e}$ Aix Marseille Univ, CNRS, ICR UMR 7273, F-13397 Marseille, France.

E-mail: frederic.dumur@univ-amu.fr

${ }^{f}$ SATIE-IFSTTAR, Université Gustave Eiffel, Campus de Marne-La-Vallée, 25,

allée des Marronniers, F-78000 Versailles, France one of the most important purposes is the good matching between the emission spectrum of the LED with the absorption of the PI. ${ }^{5,6}$ For this reason, it is important to develop new photoinitiating systems (PISs) for both types (radical and cationic) of polymerization under mild near-UV or visible light irradiation sources. In this context, many works were focused on the development of new PIs or PISs; see e.g. ref. 7-12.

Phenothiazine and their derivatives are nitrogen- and sulfur-containing heterocycles which are used in a wide range of applications, from pharmacological to biological applications. ${ }^{13,14}$ Their range of applicability is not only limited to pharmacology but these structures have also been examined in various fields such as energy conversion, ${ }^{15}$ for their intense photoluminescence or their electrochemical properties. ${ }^{16,17}$ Some phenothiazine derivatives have also shown good ability to initiate cationic photopolymerization and even the copolymerization of different monomers. ${ }^{18}$ However, due to their low absorption in the visible range, these compounds are only able to initiate polymerization processes upon excitation with UV light. ${ }^{19}$ More recently, a new series of phenothiazines has been synthesized and studied as high performance photoinitiators to initiate both FRP and CP under visible light irradiation; ${ }^{20}$ these compounds were also 

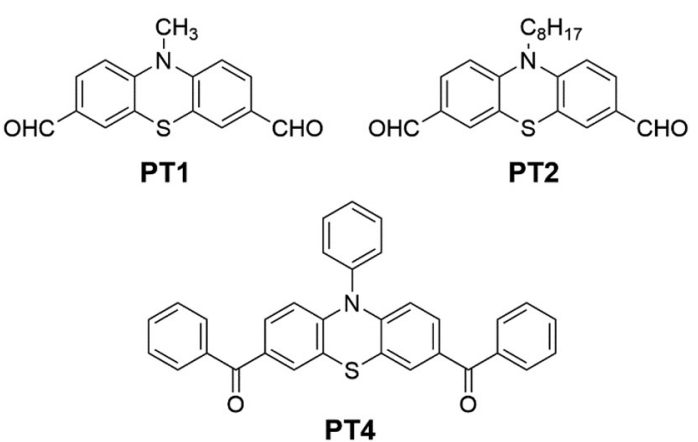

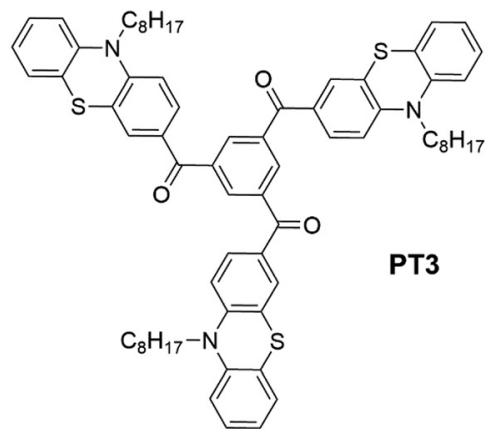

Scheme 1 The different phenothiazine derivatives investigated in this work examined for 3D printing applications. Phenothiazine derivatives were also elegantly developed as photoredox catalysts for controlled polymerization processes. ${ }^{21}$

In this new work, four phenothiazine derivatives (PT: PT1, PT2, PT3 and PT4 in Scheme 1) were specifically in silico designed by molecular modelling and used as photoinitiators/ photosensitizers of polymerization due to their excellent light absorption properties. As examples, completely new structures (e.g. PT3 and PT4) with excellent predicted light absorption properties @405 nm were selected for synthesis and more detailed photochemical investigations; this is a completely different strategy compared to a classical "trial-error" approach. The different phenothiazine derivatives were incorporated into two- and three-component (PI/iodonium (Iod) and PI/Iod/amine) photoinitiating systems (PISs) in order to induce the formation of reactive species (radicals, radical cations or acids) for both free radical (FRP) and cationic (CP) polymerizations upon visible light irradiation using a LED@405 nm. The different substituents specifically introduced on the phenothiazine core can affect the absorption properties as well as the photochemical/electrochemical properties of the targeted molecules. The photochemical properties were studied by using different methods such as photolysis, UV-Visible absorption spectroscopy, fluorimetry and cyclic voltammetry. The new PISs were compared to benchmark initiating systems. Finally, remarkable performances of these derivatives were especially shown during 3D printing experiments carried out with the (PT/Iod/NPG) systems as well as during the preparation of photocomposites using glass fibers.

\section{Experimental part}

\subsection{Synthesis of phenothiazine derivatives}

$N$-Octyl phenothiazine (1a), ${ }^{21} \mathrm{~N}$-phenyl phenothiazine (1) $),{ }^{21}$ 10-methyl-10H-phenothiazine-3,7-dicarbaldehyde (PT1 ${ }^{22}$ and 10-octyl-10H-phenothiazine-3,7-dicarbaldehyde $\quad(\text { PT2 })^{21}$ are known compounds and were prepared according to procedures previously reported in the literature. PT3 and PT4 were prepared as described below.
Synthesis of PT3. In a dry round-bottom flask, $N$-octyl phenothiazine (1a) (8.9 g, $28.57 \mathrm{mmol}$ ), 1,3,5-benzenetricarbonyl trichloride $(1.265 \mathrm{~g}, 4.76 \mathrm{mmol})$ and dry $\mathrm{CH}_{2} \mathrm{Cl}_{2}(40 \mathrm{~mL})$ were charged yielding a yellow solution. $\mathrm{AlCl}_{3}(3.8 \mathrm{~g}, 28.52 \mathrm{mmol})$ was then added in one portion leading to a violet/purple solution. The reaction mixture was stirred overnight. Water was added slowly and then the mixture was extracted with dichloromethane $(3 \times 75 \mathrm{~mL})$. The organic layers were combined, washed with water, dried over anhydrous $\mathrm{MgSO}_{4}$, filtered, and concentrated under reduced pressure. The crude product was purified by column chromatography eluting with pure dichloromethane and then with dichloromethane/ethyl acetate $(95 / 5$ to $90 / 10 \mathrm{v} / \mathrm{v})$. The desired fractions were then collected and evaporated under reduced pressure to yield the title compound as a reddish powder (1.71 g, 33\% yield). ${ }^{1} \mathbf{H}$ NMR $\left(400 \mathrm{MHz}, \mathrm{CDCl}_{3}, \delta_{\mathrm{ppm}}\right): 8.15(\mathrm{~s}, 3 \mathrm{H}), 7.55(\mathrm{~m}, 6 \mathrm{H}), 7.07(\mathrm{~m}$, $3 \mathrm{H}), 7.01(\mathrm{~m}, 3 \mathrm{H}), 6.87(\mathrm{~m}, 3 \mathrm{H}), 6.78(\mathrm{dd}, J=4.0-9.0 \mathrm{~Hz}, 6 \mathrm{H})$, $3.79(\mathrm{t}, J=7.0 \mathrm{~Hz}, 6 \mathrm{H}), 1.71(\mathrm{~m}, 6 \mathrm{H}), 1.37(\mathrm{~m}, 6 \mathrm{H}), 1.16(\mathrm{~m}$, $24 \mathrm{H}), 0.78(\mathrm{t}, J=7.0 \mathrm{~Hz}, 9 \mathrm{H}) .{ }^{13} \mathrm{C}$ NMR $\left(75 \mathrm{MHz}, \mathrm{CDCl}_{3}, \delta_{\mathrm{ppm}}\right)$ : $192.9,149.9,143.5,138.7,133.0,130.7,130.3,129.2,127.5$, 124.6, 123.7, 123.4, 115.8, 114.3, 48.0, 31.8, 29.2, 26.9, 26.7, 22.6, 14.1. HRMS (ESI+): calculated for $\mathrm{C}_{69} \mathrm{H}_{75} \mathrm{~N}_{3} \mathrm{O}_{3} \mathrm{~S}_{3}{ }^{\cdot+}\left([\mathrm{M}]^{++}\right)$: 1089.4965/found: 1089.4954.

Synthesis of PT4. In a dry round-bottom flask, $N$-phenyl phenothiazine (1b) (1.403 g, $5.1 \mathrm{mmol})$, benzoyl chloride (3.6 g, $25.5 \mathrm{mmol})$ and dry $\mathrm{CH}_{2} \mathrm{Cl}_{2}(40 \mathrm{~mL})$ were charged yielding a yellow solution. $\mathrm{AlCl}_{3}(3.4 \mathrm{~g}, 25.5 \mathrm{mmol})$ was then added in one portion leading to a violet/purple solution. The reaction mixture was stirred overnight. Water was added slowly and then the mixture was extracted with dichloromethane $(3 \times$ $75 \mathrm{~mL}$ ). The organic layers were combined, washed with water, dried over anhydrous $\mathrm{MgSO}_{4}$, filtered, and concentrated under reduced pressure. The crude product was purified by column chromatography eluting with dichloromethane. The desired fractions were then collected, evaporated under reduced pressure and precipitated into petroleum ether to yield the title compound as a bright yellow powder $(1.4 \mathrm{~g}, 57 \%$ yield $)$. ${ }^{1} \mathrm{H}$ NMR $\left(400 \mathrm{MHz}, \mathrm{CDCl}_{3}, \delta_{\mathrm{ppm}}\right): 7.74(\mathrm{~m}, 5 \mathrm{H}), 7.60(\mathrm{~m}, 5 \mathrm{H})$, $7.50(\mathrm{~m}, 4 \mathrm{H}), 7.47(\mathrm{~s}, 2 \mathrm{H}), 7.45(\mathrm{~s}, 1 \mathrm{H}), 7.41(\mathrm{~d}, J=7.6 \mathrm{~Hz}, 2 \mathrm{H})$, $6.15(\mathrm{~d}, J=8.0 \mathrm{~Hz}, 2 \mathrm{H}) .{ }^{13} \mathrm{C}$ NMR $\left(75 \mathrm{MHz}, \mathrm{CDCl}_{3}, \delta_{\mathrm{ppm}}\right): 194.3$, $137.7,133.0,132.1,131.4,130.2,130.1,129.6,128.3$, 115.2. 
HRMS (ESI+): calculated for $\mathrm{C}_{32} \mathrm{H}_{22} \mathrm{NO}_{2} \mathrm{~S}^{++}\left([\mathrm{M}+\mathrm{H}]^{\circ+}\right)$ : 484.1366/found: 484.1368 .

\subsection{Other chemical compounds}

All the other chemicals (Scheme 2) were selected with the highest purity available and used as received. Di-tert-Butyldiphenyl iodonium hexafluorophosphate (Iod or SpeedCure 938) and ethyl-4-(dimethylamino) benzoate (EDB) were obtained from Lambson Ltd (UK). (3,4-Epoxycyclohexane) methyl 3,4-epoxycyclohexylcarboxylate (EPOX; Uvacure 1500), trimethylolpropane triacrylate (TMPTA), and Ebecryl 40 were obtained from Allnex. $N$-Phenylglycine (NPG) was obtained from Sigma-Aldrich. TMPTA (or Ebecryl 40) and EPOX were selected as benchmark monomers for radical and cationic polymerization, respectively.

\subsection{Irradiation sources}

Different irradiation sources were used for the polymerization of the photocurable samples and for the photolysis experiment: (1) LED@375 nm with an incident light intensity at the sample surface $I_{0}=40 \mathrm{~mW} \mathrm{~cm}{ }^{-2}$ and (2) LED@405 $\mathrm{nm}$ with $I_{0}$ $=110 \mathrm{~mW} \mathrm{~cm}{ }^{-2}$.

\subsection{Free radical photopolymerization (FRP) and cationic photopolymerization (CP)}

In this work, phenothiazine/Iod salt couples $(0.1 \% / 1 \% \mathrm{w} / \mathrm{w})$ have been used as two-component photoinitiating systems (PISs) to initiate FRP or CP processes. The percentages for the different chemicals are related to the monomer weight. Then, these phenothiazine derivatives have been used in three-component photoinitiating systems (PT/Iod/amine (EDB or NPG)) $(0.1 \% / 1 \% / 1 \% \mathrm{w} / \mathrm{w} / \mathrm{w})$ for FRP.

The FRP of the $1.4 \mathrm{~mm}$ thick samples of TMPTA or Ebecryl 40 was carried out under air to form a rounded plastic mold $\sim 1 \mathrm{~cm}$ in diameter and $1.4 \mathrm{~mm}$ in thickness, and the FRP of the $25 \mu \mathrm{m}$ thick formulation was performed under laminate conditions (between two propylene films to reduce $\mathrm{O}_{2}$ inhibition). For CP processes, the photosensitive resin was spread on $\mathrm{a} \mathrm{BaF}_{2}$ pellet (thickness $=25 \mu \mathrm{m}$ ) and the photopolymerization was carried out under air.
The evolution of acrylate functions in TMPTA (or Ebecryl 40) and epoxy groups in EPOX was continuously followed by real-time FTIR spectroscopy (JASCO FTIR 6100) at about 1630 and $790 \mathrm{~cm}^{-1}$ for thin samples and 6160 and $3600 \mathrm{~cm}^{-1}$ for thick samples. The procedure used to monitor the photopolymerization profiles has been already described in detail. $^{23,24}$

\subsection{Redox potentials}

The redox potentials for PT compounds $\left(E_{\text {ox }}\right.$ and $\left.E_{\text {red }}\right)$ were measured in acetonitrile by cyclic voltammetry with tetrabutylammonium hexafluorophosphate as the supporting electrolyte (potentials vs. Saturated Calomel Electrode - SCE). The free energy change $\left(\Delta G_{\text {et }}\right)$ for an electron transfer reaction was calculated from eqn (1), ${ }^{25}$ where $E_{\mathrm{ox}}, E_{\mathrm{red}}, E^{*}$, and $C$ represent the oxidation potential of the electron donor, the reduction potential of the electron acceptor, the excited state energy level (determined from luminescence experiments) and the coulombic term for the initially formed ion pair, respectively. Here, $C$ is neglected as usually done for polar solvents.

$$
\Delta G_{\text {et }}=E_{\text {ox }}-E_{\text {Red }}-E^{*}+C
$$

\subsection{UV-Visible absorption and photolysis experiments}

Both the UV-Visible absorption properties and the steady-state photolysis of these compounds were studied using a JASCO V730 UV-visible spectrometer.

\subsection{Fluorescence experiments}

The fluorescence properties of the different compounds in chloroform were investigated using a JASCO FP-6200 spectrofluorimeter. The fluorescence quenching experiments of PT by Iod were investigated using the classical Stern-Volmer treatment $^{26}\left(I_{0} / I=1+k q \tau_{0}\left[\right.\right.$ Iod], where $I_{0}$ and $I$ stand for the fluorescence intensity of PT in the absence and the presence of Iod, respectively and $\tau_{0}$ stands for the lifetime of PT in the absence of Iod).

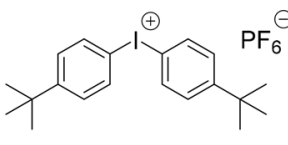

lod

(Speedcure 938)

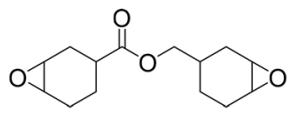

EPOX

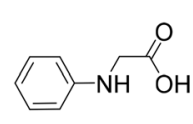

NPG

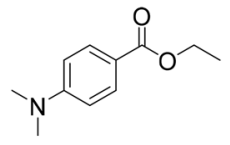

EDB

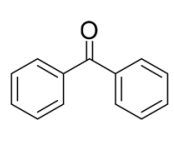

Benzophenone

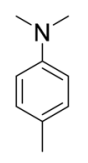

4NNTMTA
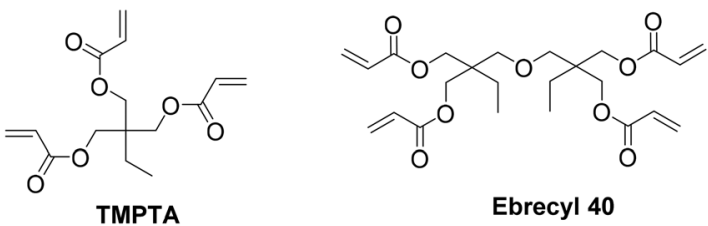

Scheme 2 Other used chemical compounds (initiators: lod, benzophenone; amine co-initiators: EDB, NPG, 4NNTMA; monomers: EPOX, TMPTA, Ebecryl 40). 


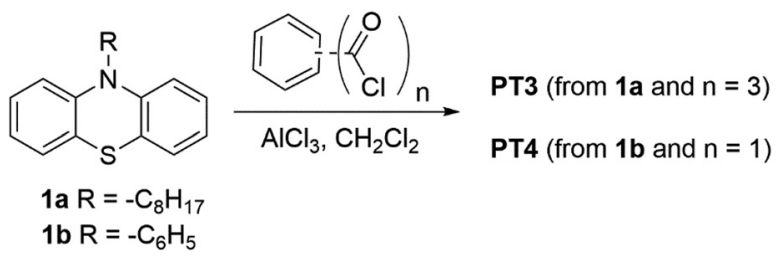

Scheme 3 Synthesis of PT3 and PT4.

\subsection{Computational procedure}

Molecular orbital calculations were carried out using the Gaussian 03 suite of programs. ${ }^{27,28}$ The electronic absorption spectra for the different compounds were calculated with the time-dependent density functional theory at the MPW1PW91FC/6-31G* level of theory on the relaxed geometries calculated at the UB3LYP/6-31G* level of theory. The triplet state energy levels were calculated at the latter level of theory.

\subsection{Near-UV conveyor}

A Dymax-LED conveyor was used to cure the composites. The glass fibers were impregnated with an organic resin (50\%/50\% $\mathrm{w} / \mathrm{w}$ ) and then irradiated. The LED conveyor was equipped with a $120 \mathrm{~mm}$ wide Teflon coated belt and one LED

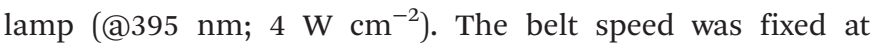
$2 \mathrm{~m} \mathrm{~min}^{-1}$.

\subsection{D printing experiments}

For 3D printing experiments, a laser diode @405 nm (spot size around $50 \mu \mathrm{m}$ ) was used for the spatially controlled irradiation. The photosensitive resin was polymerized under air and the generated 3D patterns were analysed using a numerical optical microscope (DSX-HRSU from Olympus Corporation) as presented in ref. 29 and 30.

\section{Results}

\subsection{Synthesis of light harvesting dyes}

10-Methyl-10H-phenothiazine-3,7-dicarbaldehyde (PT1) ${ }^{23}$ and 10-octyl-10H-phenothiazine-3,7-dicarbaldehyde (PT2) ${ }^{21}$ have been reported by us and others. Two other novel compounds (PT3 and PT4) have been readily synthesized from the corresponding $\mathrm{N}$-substituted phenothiazine and acyl chloride under classical Friedel-Crafts acylation conditions (Scheme 3). $N$-Octyl phenothiazine $(\mathbf{1 a})^{21}$ reacted with 1,3,5-benzenetricarbonyl trichloride giving PT3 in 33\% yield. In this reaction, 1a was used in a large excess (6.2 molar equivalents with respect to $1,3,5$-benzenetricarbonyl trichloride) in order to favor threefold benzoylation of the 1,3,5-benzenetricarbonyl central core. The excess of 1a was easily recovered during chromatography purification of the targeted compound (PT3). On the other hand, the treatment of $N$-phenyl phenothiazine $(\mathbf{1 b})^{22}$ with benzoyl chloride led to PT4 in a suitable yield (57\%). In contrast to PT3, herein benzoyl chloride was used in a large excess
(5.0 molecular equivalents with respect to $\mathbf{1 b}$ ) to force the twofold acylation on the two active sides of $\mathbf{1 b}$. Both compounds have good solubility in common organic solvents, facilitating their purification by column chromatography. Both the final compounds were characterized by NMR and HRMS analysis.

\subsection{Light absorption properties of the investigated compounds}

The UV-Visible absorption spectra of the proposed PTs in chloroform are shown in Fig. 1 and in Table 1. These compounds are characterized by high extinction coefficients $(\varepsilon)$ in the near UV and visible range (e.g. $\varepsilon(\mathbf{P T} 2)=8290 \mathrm{M}^{-1} \mathrm{~cm}^{-1}$ (a)405 $\mathrm{nm}$ and $9570 \mathrm{M}^{-1} \mathrm{~cm}^{-1}$ (a) $\lambda_{\max }$ ). Their good absorption properties ensure a good matching with the emission spectrum of the near UV or visible LEDs. Interestingly, the new synthesized compounds (PT3 and PT4) exhibit better absorption than PT1 and PT2 (Fig. 1).

From the molecular modelling data, the frontier orbitals (Highest Occupied Molecular Orbital - HOMO and Lowest Unoccupied Molecular Orbital - LUMO) involved in the lowest energy transition are depicted in Fig. 2. It can be noted that both the HOMO and LUMO are delocalized all over the $\pi$-system clearly showing a $\pi \rightarrow \pi^{*}$ lowest energy transition. For PT3 and PT4, a charge transfer transition is also observed, i.e. the HOMO and LUMO are located at different places of the molecular structure.

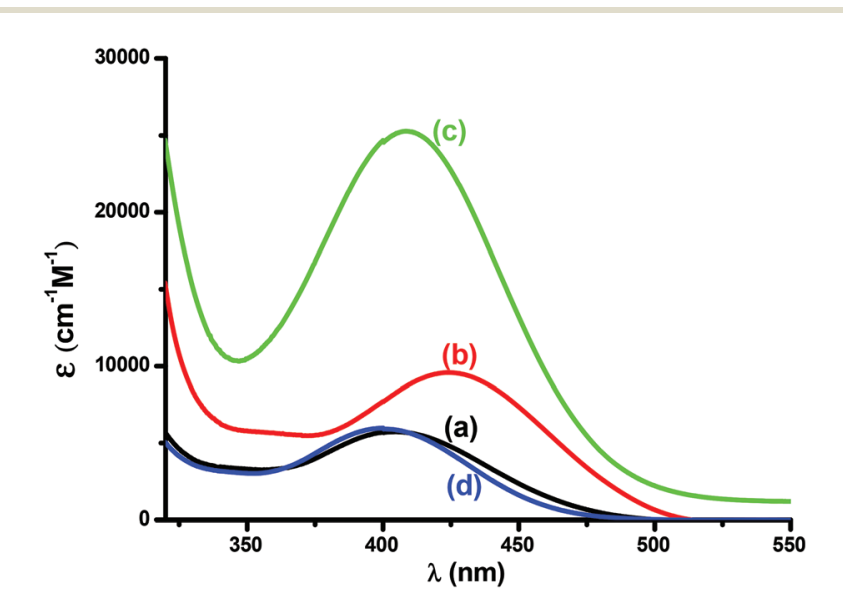

Fig. 1 Absorption spectra of the investigated compounds in chloroform: (a) PT2, (b) PT4, (c) PT3 and (d) PT1.

Table 1 Light absorption properties of PT compounds at $405 \mathrm{~nm}$ and $\lambda_{\max }$

\begin{tabular}{llcc}
\hline & $\lambda_{\max }(\mathrm{nm})$ & $\varepsilon_{\max }\left(\mathrm{M}^{-1} \mathrm{~cm}^{-1}\right)$ & $\varepsilon_{@ 405 \mathrm{~nm}}\left(\mathrm{M}^{-1} \mathrm{~cm}^{-1}\right)$ \\
\hline PT1 & 400 & 5910 & 5850 \\
PT2 & 405 & 5730 & 5730 \\
PT3 & 408 & 25280 & 25150 \\
PT4 & 424 & 9570 & 8290
\end{tabular}




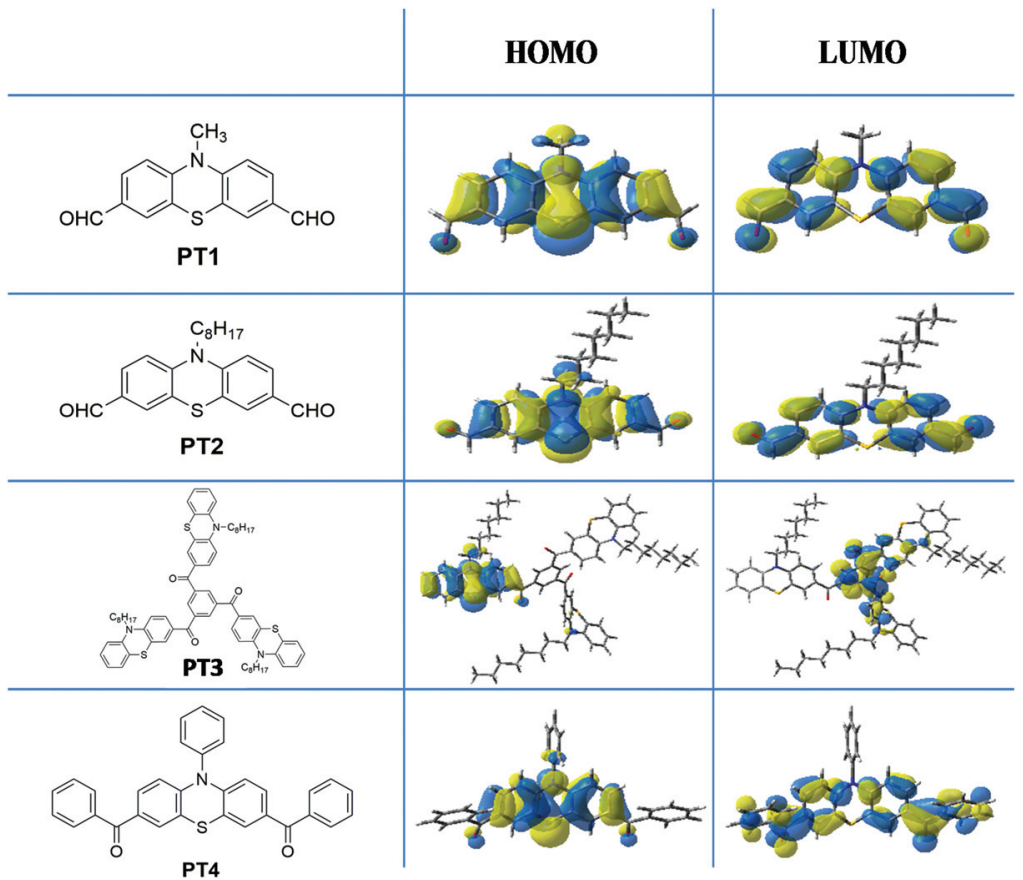

Fig. 2 Contour plots of the frontier orbitals (HOMO/LUMO) for PTs; structures optimized at the B3LYP/6-31G* level of theory.

\subsection{Free radical photopolymerization (FRP) of acrylates (TMPTA or Ebecryl 40)}

The photopolymerization profiles of the acrylate functions are reported in Fig. 3 for the benchmark monomers and the final reactive function conversions (FC) are presented in Table 2 . Different systems including PT/Iod/NPG or PT/Iod/EDB were studied. No polymerization occurs using PT alone. The different additives alone were tested before studying the effect of phenothiazine. In fact, the Iod/EDB system cannot initiate the FRP of acrylates upon exposure to a LED at $405 \mathrm{~nm}$ (Fig. 3A, B and C). However, the Iod/NPG $(1 \% / 1 \% \mathrm{w} / \mathrm{w})$ couples show a rather good efficiency for the FRP of Ebecryl 40 in thin and thick samples upon exposure to a LED at $405 \mathrm{~nm}$ (FC = $81 \%$ curve 14 in Fig. 3B for the thick samples, and $\mathrm{FC}=32 \%$ curve 14 in Fig. $3 \mathrm{C}$ for the thin samples) and also for the FRP of TMPTA ( $\mathrm{FC}=48 \%$ curve 14 in Fig. $3 \mathrm{~A}$ ). This result is probably due to a charge transfer complex (CTC) formation between Iod and NPG, ${ }^{31}$ and will be discussed in the chemical mechanism part. However, in all cases, much better polymerization rates are obtained in the presence of PT derivatives than without (curves 5-8 vs. curve 13 (Iod/EDB) and curve 14 (Iod/ NPG) in Fig. 3A, B and C). This clearly shows the crucial role of the phenothiazine derivative to improve the polymerization initiating ability.

For the two-component systems, the PT1/Iod $(0.1 \% / 1 \%$ $\mathrm{w} / \mathrm{w})$ system is the most efficient one for the FRP of Ebecryl 40 or TMPTA (thickness $=1.4 \mathrm{~mm}$, curve 4 in Fig. $3 \mathrm{~B}$ and A, respectively), while PT2/Iod is the most efficient one for the FRP of Ebecryl 40 in thin samples (curve 1 in Fig. 3C). This is in agreement with the very fast photolysis of these derivatives in the presence of Iod. The structure/reactivity/efficiency relationships will be discussed in the chemical mechanism part.

On the other hand, the PT/EDB $(0.1 \% / 1 \% \mathrm{w} / \mathrm{w})$ system shows the absence of polymerization except for PT1 which shows a poor performance in terms of the polymerization rate. These results can be ascribed to the weak interaction between PT and EDB.

Remarkably, very high performances were obtained with the introduction of the iodonium salt into the PT/EDB system which shows the huge role of the three-component systems (PT/amine/Iod) to achieve good polymerization efficiencies, e.g. $\mathrm{FC}=62 \%$ for the PT1/EDB $(0.1 \% / 1 \% \mathrm{w} / \mathrm{w})$ system after 400 $\mathrm{s}$ of irradiation and $72 \%$ for the PT1/Iod/EDB $(0.1 \% / 1 \% / 1 \%$ $\mathrm{w} / \mathrm{w} / \mathrm{w}$ ) system after $150 \mathrm{~s}$ of irradiation.

Compared to the well-established benzophenone/EDB system (Fig. 3D), both the PT/Iod and PT/Iod/amine systems exhibit much higher polymerization rates and final conversions (Fig. 3). For the benchmark 2-isopropylthioxanthone/ Iod initiating system $(0.1 / 1 \% \mathrm{wt})$, a final acrylate conversion of $55 \%$ is obtained vs. $62-71 \%$ for PT/Iod (Table 2) showing again the interest of the proposed PT/Iod initiating systems.

The ability of the different PT/Iod systems to initiate FRP under laminate conditions (thickness $=25 \mu \mathrm{m}$ ) under exposure to a LED at $405 \mathrm{~nm}$, follows the order: PT1 $>$ PT2 $>$ PT4 $>$ PT3. These initiating abilities can be governed by different parameters such as their absorption properties, the photolysis behavior, free-energy change for the electron transfer reaction $\left(\Delta G_{\mathrm{et}}\right)$ and the electron transfer quantum yields. This point will be discussed below. 

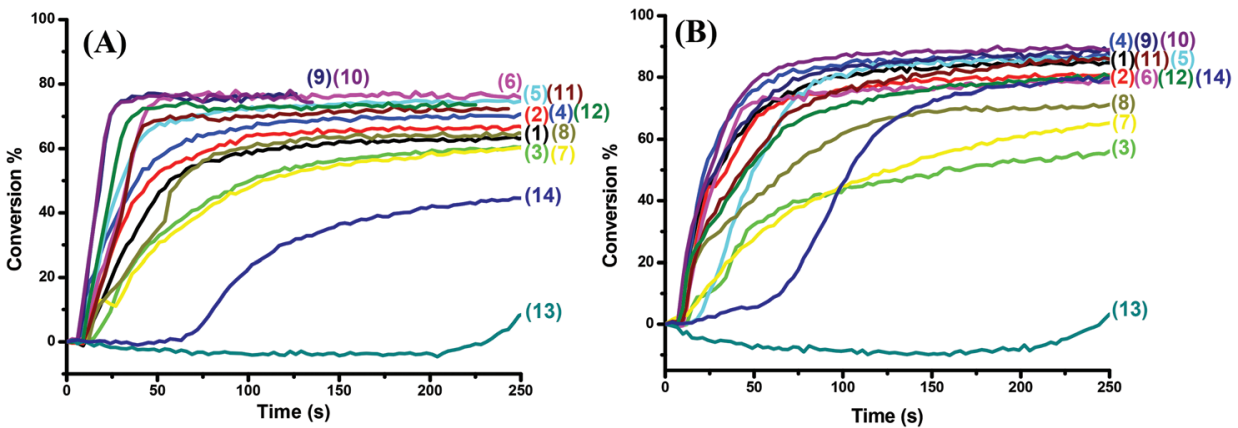

1
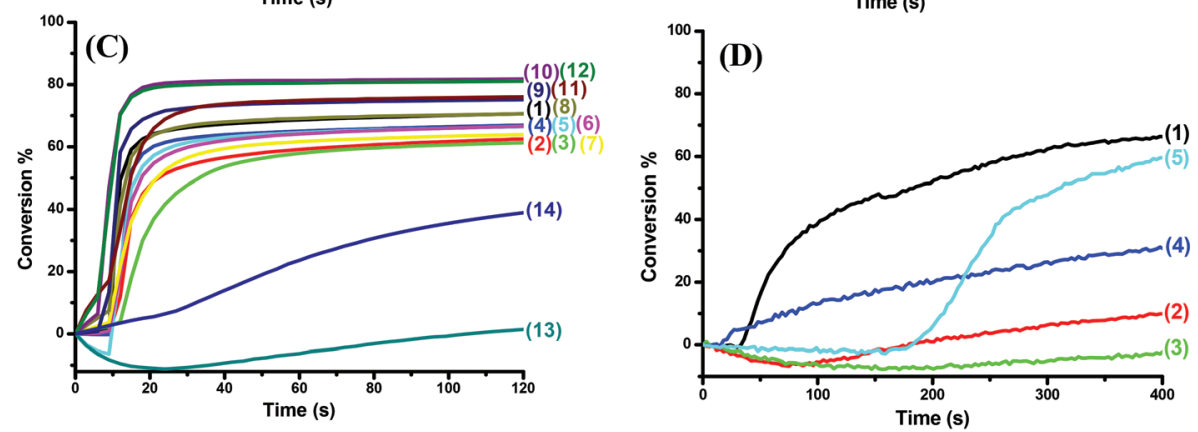

Fig. 3 Polymerization profiles (acrylate function conversion vs. irradiation time) for (A) TMPTA (thickness $=1.4 \mathrm{~mm}$ ), (B) Ebecryl 40 (thickness = $1.4 \mathrm{~mm}$ ), and (C) Ebecryl 40 (thickness $=25 \mu \mathrm{m}$ ) upon exposure to the LED $(405 \mathrm{~nm}$ in the presence of the two- or three-component photoinitiating systems: (1) PT2/lod (0.1\%/1\% w/w), (2) PT4/lod (0.1\%/1\% w/w), (3) PT3/lod (0.1\%/1\% w/w), (4) PT1/lod (0.1\%/1\% w/w), (5) PT2/lod/EDB (0.1\%/1\%/1\% w/w/w), (6) PT4/lod/EDB (0.1\%/1\%/1\% w/w/w), (7) PT3/lod/EDB (0.1\%/1\%/1\% w/w/w), (8) PT1/lod/EDB (0.1\%/1\%/1\% w/w/w), (9) PT2/lod/NPG (0.1\%/ 1\%/1\% w/w/w), (10) PT4/lod/NPG(0.1\%/1\%/1\% w/w/w), (11) PT3/lod/NPG (0.1\%/1\%/1\% w/w/w), (12) PT1/lod/NPG (0.1\%/1\% /1\% w/w/w), (13) lod/EDB $(1 \% / 1 \% \mathrm{w} / \mathrm{w})$, and $(14) \mathrm{lod} / \mathrm{NPG}(1 \% / 1 \% \mathrm{w} / \mathrm{w})$. Irradiation starts at $t=10 \mathrm{~s}$. (D) Polymerization profiles (acrylate function conversion vs. irradiation time) for an Ebecryl 40 resin (thickness $=1.4 \mathrm{~mm}$ ) upon exposure to the LED@405 nm in the presence of the two-component photoinitiating systems: (1) PT2/EDB (0.1\%/1\% w/w), (2) PT4/EDB (0.1\%/1\% w/w), (3) PT3/EDB (0.1\%/1\% w/w), (4) PT1/EDB (0.1\%/1\% w/w), and (5) benzophenone/ $\operatorname{EDB}(0.1 \% / 1 \% \mathrm{w} / \mathrm{w})$.

Table 2 Final acrylate function conversion (FC) for TMPTA and Ebecryl 40 using different photoinitiating systems after $400 \mathrm{~s}$ of irradiation with the LED@405 nm (thickness $=1.4 \mathrm{~mm}$ )
(PT/Iod system) upon irradiation with a LED at $405 \mathrm{~nm}$. Interestingly, these systems $(0.15 \% / 2 \% \mathrm{w} / \mathrm{w})$ lead to good polymerization efficiency, i.e. both high final conversions and good polymerization rates were obtained in thick samples (FC $=42 \% ; 40 \%$ and $39 \%$ for PT2, PT4 and PT1, respectively) and in thin samples (FC $=50 \% ; 47 \%$ for PT2 and PT3, respectively) (Fig. 4).

For these irradiation conditions, when using Iod or PT alone, no polymerization occurs, showing the key role of the PT/Iod systems when using LED@405 nm. A new peak ascribed to the polyether network can be easily observed at $\sim 1080 \mathrm{~cm}^{-1}$ (Fig. 4C). The efficiency for CP (i.e. for Rp) clearly follows the trend PT2 > PT3 > PT1 > PT4. This behavior is not directly related to their respective light absorption properties because PT3 is less effective compared to PT2 but it has the highest extinction coefficient among the different PTs. This may be due to their photochemical reactivity which also plays a very important role (see below in the chemical mechanism part).

\subsection{D printing experiments using PT/Iod or PT/Iod/amine systems}

3D printing experiments were performed in the presence of the PT/Iod/amine systems in Ebecryl 40 (Fig. 5). Indeed, the high photosensitivity of these resins (see above) allows an 

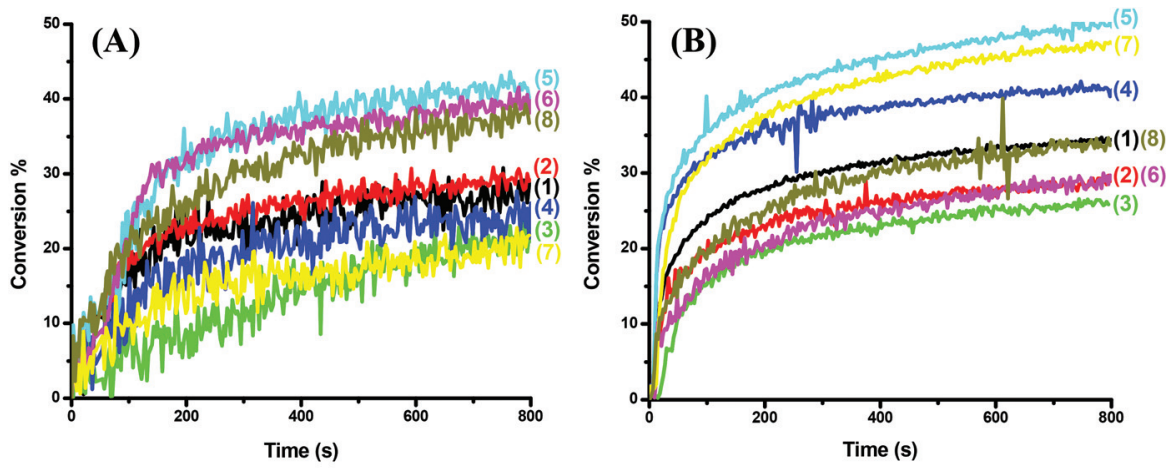

(C)
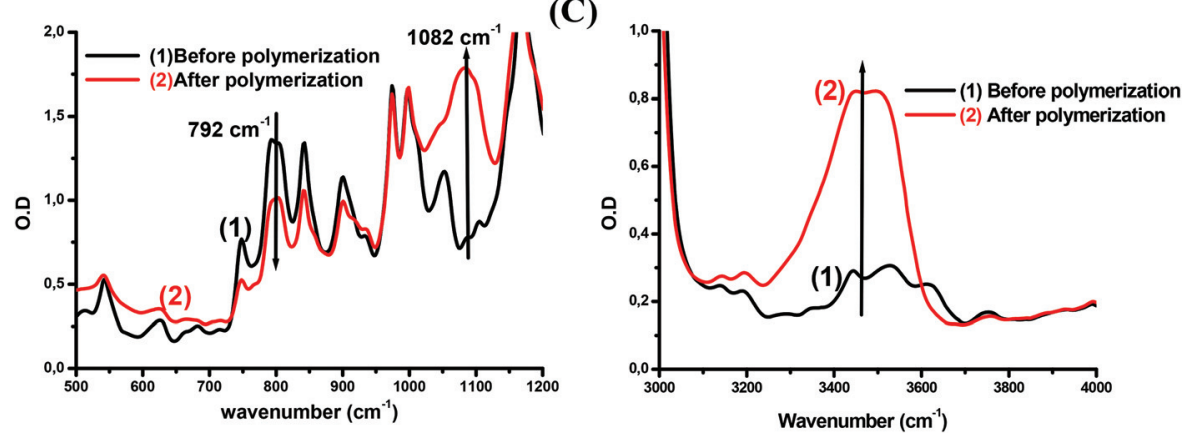

Fig. 4 Polymerization profiles (epoxy function conversion vs. irradiation time) for EPOX in (A) a thick sample (1.4 mm) and (B) a thin sample upon exposure to the LED@405 $\mathrm{nm}$ in the presence of the two-component photoinitiating systems: (1) PT2/lod (0.1\%/1\% w/w), (2) PT4/lod (0.1\%/1\% w/w), (3) PT3/lod (0.1\%/1\% w/w), (4) PT1/lod (0.1\%/1\% w/w), (5) PT2/lod $(0.15 \% / 2 \% \mathrm{w} / \mathrm{w}),(6)$ PT $4 / \mathrm{lod}(0.15 \% / 2 \% \mathrm{w} / \mathrm{w}),(7)$ PT3/lod $(0.15 \% / 2 \% \mathrm{w} / \mathrm{w})$, and $(8)$ PT1/lod $(0.15 \% / 2 \% \mathrm{w} / \mathrm{w})$. Irradiation starts at $t=10 \mathrm{~s}$. (C) IR spectra recorded before and after polymerization for PT2/lod $(0.15 \% / 2 \% \mathrm{w} / \mathrm{w})$ in $\mathrm{EPOX}$.

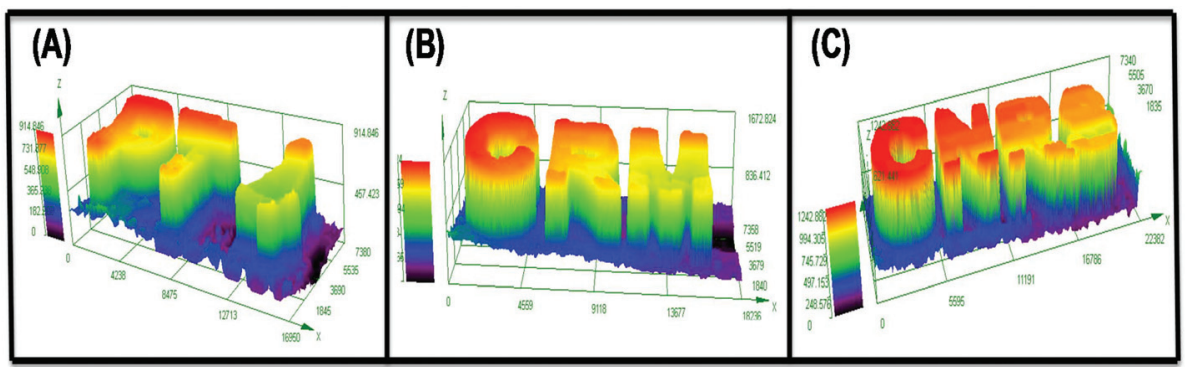

Fig. 5 Characterization of the 3D patterns by numerical optical microscopy: (A) PT4/lod (0.04\%/0.4\% w/w) in Ebecryl 40; (B) PT1/lod/amine (4-N, $N$-trimethylaniline) $(0.04 \% / 0.4 \% / 0.11 \% \mathrm{w} / \mathrm{w})$ in Ebecryl 40 and (C) PT2/lod (0.04\%/0.4\% w/w) in Ebecryl 40.

efficient polymerization process in the irradiated area. Thick polymer samples were obtained in a short writing time ( $\sim 2 \mathrm{~min})$. Representative 3D patterns were characterized by numerical optical microscopy (Fig. 5). The spatial resolution is excellent (only limited by the size of the laser diode beam: spot of $50 \mu \mathrm{m})$. The thickness for one printed layer $(900 \mu \mathrm{m}$ in Fig. 5A to $1.2 \mathrm{~mm}$ in Fig. $5 \mathrm{C}$ ) is very high for 3D printing with this high spatial resolution.

\subsection{Photocomposite preparation using the LED conveyor}

Nowadays, photopolymerization of composites is used for different applications such as the curing of dental cements ${ }^{32,33}$ and others. ${ }^{34,35}$ The principal shortcoming of the photopolymerization process applied to composite formulations is the limited light penetration strongly reducing the potential depth of cure. However, the main advantages of composites are their high strength and relatively low weight. Therefore, an efficient access to curing in depth is highly desired and new PISs are urgently required for such an application.

In this work, the glass fibers were impregnated with an organic resin in the presence of PIS (Ebecryl 40 or TMPTA) (50\% glass fibers $50 \%$ resin; thickness of the composite $=$ $2 \mathrm{~mm}$ ) and were irradiated with a LED conveyor. Remarkably, only one pass needs to be used to completely cure the composite in the presence of the PT/Iod/amine (amine = NPG) $(0.1 \%$ / $1 \% / 1 \% \mathrm{w} / \mathrm{w} / \mathrm{w}$ ) systems (both the surface and the bottom are tack-free). The results are summarized in Fig. 6. This shows that the PT/Iod/amine $(0.1 \% / 1 \% / 1 \% \mathrm{w} / \mathrm{w} / \mathrm{w})$ three-component 
Before irradiation

(1)

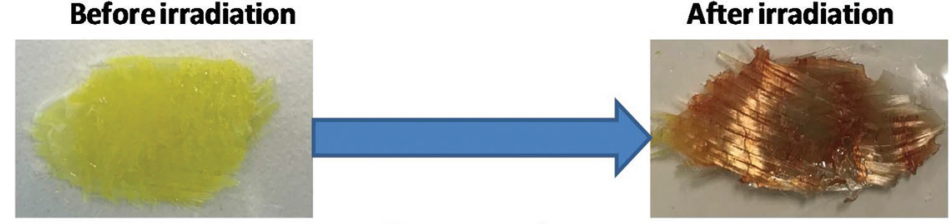

One pass only.

(2)

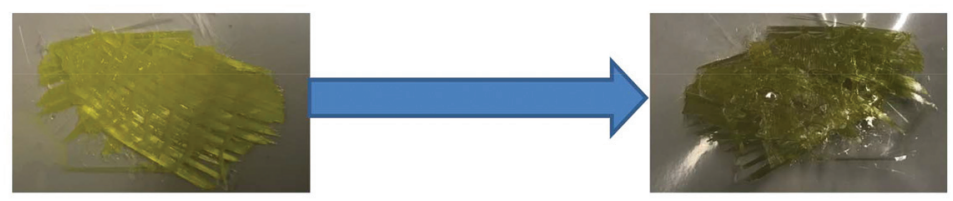

Tack - free at the surface

(3)

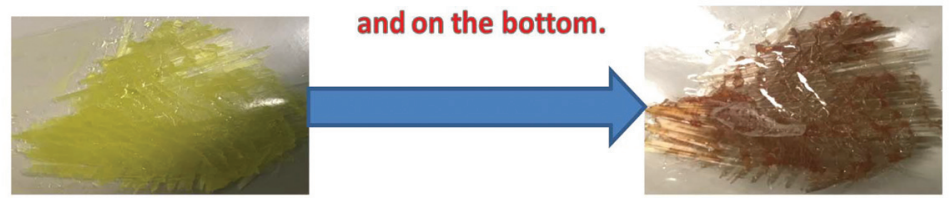

1

Fig. 6 Photocomposites produced upon exposure to near-UV light (LED@395 nm), belt speed = $2 \mathrm{~m} \mathrm{~min}^{-1}$, using free radical polymerization (FRP) in the presence of glass fibers/acrylate resin for different systems: (1) PT2/lod/NPG $(0.1 \% / 1 \% / 1 \% \mathrm{w} / \mathrm{w} / \mathrm{w}) ;(2)$ PT4/lod/NPG $(0.1 \% / 1 \% / 1 \% \mathrm{w} / \mathrm{w} / \mathrm{w}) ;$ and (3) PT2/lod/NPG $(0.1 \% / 1 \% / 1 \%)$ in TMPTA.

systems can be used for curing composites upon near-UV light irradiation.

\section{Discussion}

To discuss the polymerization results obtained above, the chemical mechanisms must be established for a better understanding of the PT structure/reactivity/efficiency relationship.

\subsection{Steady-state photolysis}

Different steady-state photolysis experiments for the investigated PTs are shown in Fig. 7. Photolysis of the PT1/Iod system in chloroform upon irradiation with a LED@375 nm is faster than for PT1 alone which is very photostable (Fig. 7B vs. 7A, respectively), i.e. a strong interaction between PT1 and Iod clearly occurs. The same behaviour is observed with the other PTs. A new photoproduct (characterized by a significant new absorption between 300 and $390 \mathrm{~nm}$ ) is formed due to this
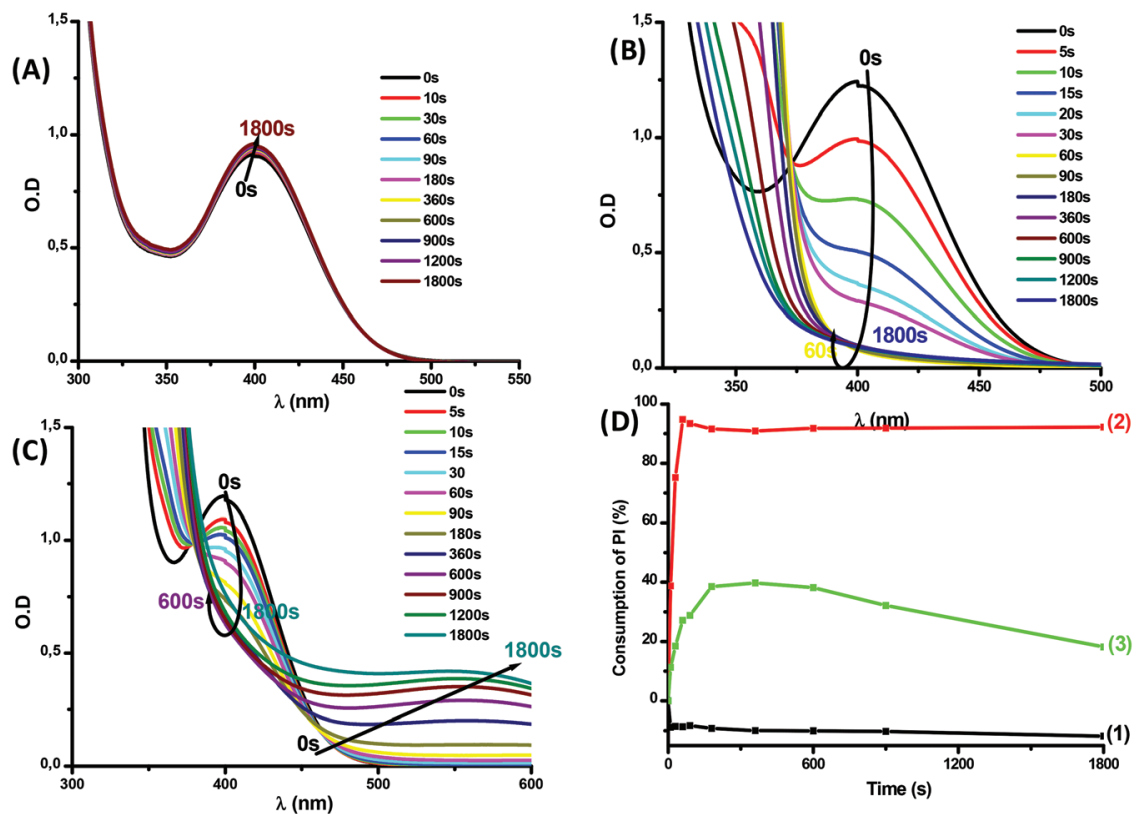

Fig. 7 (A) Photolysis of PT1 in the absence of lod; (B) PT1/lod photolysis; and (C) PT1/lod/EDB photolysis. (D) Consumption of PT1: (1) without lod, (2) with lod $\left(10^{-2} \mathrm{M}\right)$ and (3) with lod and EDB $\left(10^{-2} \mathrm{M}\right)$ vs. irradiation time - upon exposure to the LED@375 $\mathrm{nm}$ in chloroform. 
PT1/Iod interaction. In the presence of both EDB and Iod, the photolysis of PT is slower than with Iod. Indeed, the percentage of consumption of PT is depicted in Fig. 7D where this percentage is measured as a function of the irradiation time in the presence of Iod and Iod/EDB or even for PT alone.

\subsection{Fluorescence quenching and cyclic voltammetry}

Fluorescence and fluorescence quenching experiments were carried out for the different PTs in chloroform (see Fig. 8A). The crossing point of the absorption and fluorescence spectra allows the evaluation of the first singlet excited state energy levels $\left(E_{\mathrm{S}_{1}}\right)$ (e.g. for PT1: $\sim 2.61 \mathrm{eV}$; Table 3 and Fig. 8B). In addition, an efficient fluorescence quenching of PT1 by Iod was observed with a high value of the Stern-Volmer coefficient $\left(K_{\mathrm{SV}}\right)$ (for PT1/Iod interaction $K_{\mathrm{SV}}=111.8 \mathrm{M}^{-1}$, Fig. $8 \mathrm{C}$ ). Therefore, very high electron transfer quantum yields from the excited singlet state $\phi_{\mathrm{S}_{1}}\left(\right.$ e.g. $\phi_{\mathrm{ets}_{1}}=0.70$ for PT1/Iod) were calculated from the equation (eqn (2)) (Table 3):

$$
\phi_{\mathrm{etS}_{1}}=K_{\mathrm{SV}}[\operatorname{Iod}] /\left(1+K_{\mathrm{SV}}[\operatorname{Iod}]\right)
$$

The free energy changes $\left(\Delta G_{\text {et }}\right)$ for the electron transfer reaction between PTs (as electron donors) and Iod (an electron acceptor) were calculated from eqn (1) using the oxidation potentials $E_{\mathrm{OX}}$ (Fig. 8D and Table 3 ) and the excited state energies $\left(E_{\mathrm{S}_{1}}\right)$ of PTs. In full agreement with the high $K_{\mathrm{SV}}$ determined above, these processes from $\mathrm{S}_{1}$ are found to be favorable $\left(\Delta G_{\text {et }}<0\right)$, e.g. PT1 with Iod $\Delta G_{\text {ets }_{1}}=-1.58 \mathrm{eV}$ and PT4 with Iod $\Delta G_{\text {ets }_{1}}=-1.57 \mathrm{eV}$ (Table 3).

In contrast, no quenching was observed for the PT/EDB interaction. These results are in full agreement with the photopolymerization results which show a much better initiating performance for the $\mathrm{PT} / \mathrm{Iod} v s$. PT/EDB initiating systems. It
Table 3 Parameters characterizing the photochemical mechanisms associated with ${ }^{1}$ phenothiazine/lod in chloroform

\begin{tabular}{llllll}
\hline & $E_{\text {ox }}(\mathrm{V}$ per SCE $)$ & $E_{\mathrm{S}_{1}}(\mathrm{eV})$ & $\Delta G_{\mathrm{S}_{1}}(\mathrm{eV})$ & $K_{\mathrm{SV}}$ & $\Phi_{\text {et }(\mathrm{PT} / \mathrm{Iod})}$ \\
\hline PT1 & 0.78 & 2.58 & -1.6 & 250 & 0.8 \\
PT2 & 0.75 & 2.52 & -1.57 & 114 & 0.7 \\
PT3 & 0.77 & 2.45 & -1.48 & 5.7 & 0.25 \\
PT4 & 0.83 & 2.61 & -1.58 & 112 & 0.7
\end{tabular}

should be noted that the PT/Iod interaction corresponds to a photo-oxidation process for the phenothiazine derivatives.

Based on these results, a global mechanism is proposed ((1)-(8)) (according to other dyes in dye/Iod/amine systems ${ }^{6}$ ) showing the formation of the reactive species for CP and FRP $\left({ }^{1,3} \mathrm{PT}\right.$ stands for the singlet and triplet excited states of PT). A charge transfer complex (CTC) can be formed between amine (electron donor) and Iod (electron acceptor); this complex leads to the formation of $\operatorname{Ar}^{\circ}((3)$ and (4)). (7) and (8) are proposed for the three-component systems regenerating the PT in agreement with a lower consumption of the PT for these threecomponent systems. This regeneration of PT suggests a partial photoredox catalyst behaviour. Overall, $\mathrm{NPG}_{\left(-\mathrm{H},-\mathrm{CO}_{2}\right)^{\circ}, \mathrm{Ar}}{ }^{\bullet}$ and $\mathrm{NPG}_{\left(-\mathrm{H},-\mathrm{CO}_{2}\right)}{ }^{+}, \mathrm{PT}^{\cdot+}$ are the responsible species for FRP and $\mathrm{CP}$, respectively.

$$
\begin{gathered}
\mathrm{PT} \rightarrow{ }^{1,3} \mathrm{PT}^{*}(h \nu) \\
{ }^{1,3} \mathrm{PT}^{*}+\mathrm{ArI}^{+} \rightarrow \mathrm{Ar}^{*}+\mathrm{ArI}+\mathrm{PT}^{\cdot+} \\
\mathrm{NPG}+\mathrm{Iod} \rightarrow[\mathrm{NPG}-\mathrm{Iod}]_{\mathrm{CTC}} \\
{[\mathrm{NPG}-\mathrm{Iod}]_{\mathrm{CTC}} \rightarrow \mathrm{Ar}^{\cdot}} \\
{ }^{1,3} \mathrm{PT}+\mathrm{NPG} \rightarrow{\mathrm{PT}-\mathrm{H}^{*}+\mathrm{NPG}_{(-\mathrm{H})}}^{\cdot}
\end{gathered}
$$

Q7

Fig. 8 (A) Fluorescence quenching of PT1 by lod, (B) singlet state determination in chloroform for PT1, (C) Stern-Volmer treatment for PT1/lod fluorescence quenching, and (D) cyclic voltammetry for PT1 oxidation. 


$$
\begin{aligned}
& \mathrm{NPG}_{\left(-\mathrm{H} ;-\mathrm{CO}_{2}\right)^{\bullet}}+\mathrm{Ar}_{2} \mathrm{I}^{+} \rightarrow \mathrm{NPG}_{\left(-\mathrm{H} ;-\mathrm{CO}_{2}\right)}{ }^{+}+\mathrm{Ar}+\operatorname{ArI} \\
& \mathrm{PT}^{\cdot} \mathrm{H}^{\cdot}+\mathrm{Ar}_{2} \mathrm{I}^{+} \rightarrow \text { Phenothiazine }+\mathrm{H}^{+}+\mathrm{ArI}+\mathrm{Ar}
\end{aligned}
$$

\subsection{Phenothiazine derivatives as photoredox catalysts in three-component systems}

Interestingly, a photoredox catalyst behavior was observed, where a high performance of the FRP of TMPTA in a thick or thin sample is shown, when an amine was introduced in the formulation in order to regenerate the phenothiazine derivative ((5) and (8)). The effect of EDB is clearly manifested by an increase of the final conversion for all phenothiazine-based systems $(75 \%$ for PT2/Iod/EDB $(0.1 \% / 1 \% / 1 \% \mathrm{w} / \mathrm{w} / \mathrm{w})$ compared to $64.5 \%$ for PT2/Iod $(0.1 \% / 1 \% \mathrm{w} / \mathrm{w})$, and $76 \%$ for PT $4 / \mathrm{Iod} /$ EDB $(0.1 \% / 1 \% / 1 \% \mathrm{w} / \mathrm{w} / \mathrm{w})$ compared to $67 \%$ PT $4 / \operatorname{Iod}(0.1 \% /$ $1 \% \mathrm{w} / \mathrm{w})$. This photoredox catalyst behaviour for PT derivatives is also in agreement with a lower consumption of PT in the three-component system $v s$. the two-component ones (Fig. 7D, curve $3 v$ s. curve 2) showing a regeneration through (8).

\section{Conclusion}

In this article, four in silico developed phenothiazine derivatives showed very high performance in FRP and CP upon irradiation with a LED at $405 \mathrm{~nm}$. Indeed, three of these phenothiazines have been classified as photoredox catalysts (they can be - at least - partly regenerated in three-component systems). These derivatives are very powerful for 3D printing as well as for the synthesis of photocomposites. In the future, it is important to develop new phenothiazine derivatives by shifting their absorption spectra towards the NIR region for a greater absorption for thick samples and consequently higher conversion rates.

\section{Conflicts of interest}

\section{Acknowledgements}

The Lebanese group would like to thank "The Association of Specialization and Scientific Guidance" (Beirut, Lebanon) for funding and supporting this scientific work. JL thanks the region Grand-Est for the funding of the project MIPPI-4D.

\section{References}

1 N. Zivic, M. Bouzrati-Zerelli, A. Kermagoret, F. Dumur, J.-P. Fouassier, D. Gigmes and J. Lalevee, Polym. Chem., 2016, 7, 5873-5879.
2 M. Schmitt, RSC Adv., 2015, 5, 67284-67298.

3 M. Schmitt and J. Lalevée, Colloids Surf., A, 2017, 532, 189194.

4 C. Dietlin, S. Schweizer, P. Xiao, J. Zhang, F. Morlet-Savary, B. Graff, J.-P. Fouassier and J. Lalevee, Polym. Chem., 2015, 6, 3895-3912.

5 J. V. Crivello, Photoinitiators for Free Radical, Cationic; Anionic Photopolymerization, John Wiley \& Sons, Chichester, 2nd edn, 1998.

6 J. P. Fouassier and J. Lalevée, Photoinitiators for Polymer Synthesis-Scope, Reactivity, and Efficiency, Wiley-VCH Verlag GmbH \& Co. KGaA, Weinheim, 2012.

7 D. Neshchadin, A. Rosspeintner, M. Griesser, B. Lang, S. Mosquera-Vazquez, E. Vauthey, V Gorelik, R Liska, C Hametner, B Ganster, et al., J. Am. Chem. Soc., 2013, 135, 17314-17321.

8 M. Kara, S. Dadashi-Silab and Y. Yagci, Macromol. Rapid Commun., 2015, 36, 2070-2075.

9 Y. Yagci, S. Jockusch and N.J. Turro, Macromolecules, 2010, 43, 6245-6260.

10 J. Wang, S. Stanic, A.A. Altun, M. Schwentenwein, K. Dietliker, L. Jin, J. Stampfl, S. Baudis, R. Liska and H. Grützmacher, Chem. Commun., 2018, 54, 920-923.

11 T.N. Eren, B. Graff, J. Lalevee and D. Avci, Prog. Org. Coat., 2019, 128, 148-156.

12 J. Radebner, A. Eibel, M. Leypold, N. Jungwirth, T. Pickl, A. Torvisco, R. Fischer, U.K. Fischer, N. Moszner, G. Gescheidt, et al., Chem. - Eur. J., 2018, 24, 8281-8285.

13 G. Jaouen, S. Top, A. Vessieres, G. Leclercq and M. J. McGlinchey, Curr. Med. Chem., 2004, 11, 2505-2517.

14 K. Pluta, B. Morak-Mlodawska and M. Jelen, Eur. J. Med. Chem., 2011, 46, 3179-3189.

15 W. J. Albery, A. W. Foulds, K. J. Hall, A. R. Hillman, R. G. Edgell and A. F. Orchard, Nature, 1979, 282, 793-797.

16 M. Okazaki, Y. Takeda, P. Data, P. Pander, H. Higginbotham, P. Monkman and S. Minakata, Chem. Sci., 2017, 8, 2677-2686.

17 Z.Q. Zhang, Z. Wu, J.B. Sun, B.Q. Yao, G.H. Zhang, P.C. Xue and R. Lu, J. Mater. Chem. C, 2015, 3, 4921-4932.

18 Z. Gomurashvili and J. V. Crivello, Macromolecules, 2002, 35, 2962-2969.

19 P. Chao, R. Gu, X. Ma, T. Wang and Y. Zhao, Polym. Chem., 2016, 7, 5147-5156.

20 M. Abdallah, T. -T. Bui, F. Goubard, D. Theodosopoulou, F. Dumur, A. Hijazi, J.-P. Fouassier and J. Lalevée, Polym. Chem., 2019, 10, 6145-6156.

21 N. J. Treat, H. Sprafke, J. W. Kramer, P. G. Clark, B. E. Barton, J. Read De Alaniz, B. P. Fors and C. J. Hawker, J. Am. Chem. Soc., 2014, 136, 16096-16101.

22 L. Marin, A. Bejan, D. Ailincai and D. Belei, Eur. Polym. J., 2017, 95, 127-137.

23 A. Mousawi, A. Kermagoret, D.L. Versace, J. Toufaily, T. Hamieh, B. Graff, F. Dumur, D. Gigmes, J.P. Fouassier and J. Lalevee, Polym. Chem., 2016, 8, 568-580.

24 A. Al Mousawi, C. Dietlin, B. Graff, F. Morlet-Savary, J. Toufaily, T. Hamieh, J.P. Fouassier, A. Chachaj-Brekiesz,
1 
J. Ortyl and J. Lalevee, Macromol. Chem. Phys., 2016, 217, 1955-1965.

25 D. Rehm and A. Weller, Isr. J. Chem., 1970, 8, 259-271.

26 J.P. Fouassier, Photoinitiator, Photopolymerization and Photocuring: Fundamentals and Applications, Hanser Publishers, Munich, 1995.

27 J. B. Foresman and A. Frisch, Exploring Chemistry with Electronic Structure Methods, Gaussian Inc., Pittsburgh, PA, 2nd edn, 1996.

28 M. J. Frisch, G. W. Trucks, H. B. Schlegel, G. E. Scuseria, M. A. Robb, J. R. Cheeseman, V. G. Zakrzewski, J. A. Montgomery, J. R. E. Stratmann, J. C. Burant, S. Dapprich, J. M. Millam, A. D. Daniels, K. N. Kudin, M. C. Strain, O. Farkas, J. Tomasi, V. Barone, M. Cossi, R. Cammi, B. Mennucci, C. Pomelli, C. Adamo, S. Clifford, J. Ochterski, G. A. Petersson, P. Y. Ayala, Q. Cui, K. Morokuma, P. Salvador, J. J. Dannenberg, D. K. Malick, A. D. Rabuck, K. Raghavachari, J. B. Foresman, J. Cioslowski, J. V. Ortiz, A. G. Baboul, B. B. Stefanov, G. Liu, A. Liashenko, P. Piskorz, I. Komaromi, R. Gomperts, R. L. Martin, D. J. Fox, T. Keith, M. A. Al-Laham, C. Y. Peng,
A. Nanayakkara, M. Challacombe, P. M. W. Gill, 1 B. Johnson, W. Chen, W. M. Wong, J. L. Andres, C. Gonzalez, M. Head-Gordon, E. S. Replogle and J. A. Pople, Gaussian 03, Revision B-2, Gaussian Inc., Pittsburgh, PA, 2003.

29 J. Zhang, F. Dumur, P. Xiao, B. Graff, D. Bardelang, D. Gigmes, J.-P. Fouassier and J. Lalevee, Macromolecules, 2015, 48, 2054-2063.

30 P. Xiao, F. Dumur, J. Zhang, J.-P. Fouassier, D. Gigmes and J. Lalevee, Macromolecules, 2014, 47, 3837-3844.

31 P. Garra, B. Graff, F. Morlet-Savary, C. Dietlin, J. M. Becht, J.-P. Fouassier and J. Lalevée, Macromolecules, 2018, 51, 5770.

32 S. Bayou, M. Mouzali, F. Aloui, L. Lecamp and P. Lebaudy, Polymer, 2013, 45, 863-870.

33 J. Vreven, A. Raskin, J. Sabbagh, G. Vermeersch and G. Leloup, Résines composites EMC, Odontologie, 2005.

34 P. Kardar, M. Ebrahimi and S. Bastani, J. Therm. Anal. Calorim., 2014, 118, 541-549.

35 P. Kardar, M. Ebrahimi and S. Bastani, Pigm. Resin Technol., 2014, 43, 177-184. 